\title{
DERECHO Y FISCALIDAD EN LA CONSTRUCCIÓN DE UNA FRONTERA INTERNA EN LA CORONA DE ARAgón (RIBAgORZA, 1250-1300)
}

\section{GUILLERMO TOMÁs FACI \\ Universidad de Zaragoza*}

\begin{abstract}
RESUMEN: Hasta la mitad del siglo XIII la línea fronteriza que separaba Aragón de Cataluna era tan difusa como sus respectivas identidades políticas. Sin embargo, en las últimas décadas de la centuria ambos territorios se configuraron como entidades administrativas diferenciadas, como resultado del auge del poder centralizado de los monarcas de la Corona de Aragón y de su peculiar organización territorial; una consecuencia lógica de ello fue la emergencia progresiva de una nitida frontera interna, anteriormente inexistente. El encaje de Ribagorza en uno de los lados de la nueva divisoria generó discrepancias, no solo entre las élites políticas aragonesas y catalanas, sino también entre las propias fuerzas sociales de la zona. En este artículo se pretende mostrar que los distintos intereses de estas últimas en aspectos como el derecho escrito o la fiscalidad extraordinaria fueron la clave del conflicto.
\end{abstract}

Palabras Clave: Frontera. Estado. Derecho escrito. Fiscalidad. Ribagorza. Corona de Aragón. Siglo XIII.

Guillermo Tomás Faci es miembro del Departamento de Historia Medieval de la Universidad de Zaragoza. Dirección para correspondencia: Facultad de Filosofía y Letras, C/ Pedro Cerbuna, 12, 50009, Zaragoza. Correo electrónico: guitofa@unizar.es.

* El presente trabajo se ha realizado gracias a una beca de Formación del Personal Investigador del Gobierno de Aragón (ref. B71-08), y se inscribe en las líneas de investigación del Grupo de Investigación de Excelencia C.E.M.A. (www.unizar.es/cema); agradezco la lectura crítica e indicaciones de los catedráticos Carlos Laliena y Ángel Sesma, así como de Mario Lafuente, Santiago Simón y Sandra de la Torre. Se han empleado las siguientes abreviaturas: $A C A=$ Archivo de la Corona de Aragón, sección de Real Cancillería; ACL=Archivo de la Catedral de Lérida; $\mathrm{BABLB}=$ Boletín de la Real Academia de Buenas Letras de Barcelona; BNE = Biblioteca Nacional de España; $C D G=$ Mur LAENCUENTRA, Jorge, "Colección diplomática de Graus», CD anexo a Septembris: historia y vida cotidiana en Graus entre los siglos XI y XV. Ayuntamiento de Graus, 2003; CDSV = MARTín DuQUE, Ángel J., Colección diplomática del monasterio de San Victorián de Sobrarbe (1000-1219), Zaragoza, Departamento de Historia Medieval, 2004. 
LAW AND TAXATION IN THE CONSTRUCTION OF AN INTERNAL FRONTIER IN THE KINGDOM OF ARAGON (RIBAGORZA 1250-1300)

ABSTRACT: Until the middle of the 13th century, the border which divided Aragon from Catalonia was as vague as their respective political identities. However, in the last decades of that century both countries became differentiated administrative structures, as a result of development of state power of the Crown of Aragon's kings, and of its characteristic territorial organisation; the natural consequence was that the previously non-existent internal frontier came about gradually. The insertion of Ribagorza on one side of the new border caused disagreements, not just among the Catalan and Aragonese political elites, but also among the local social forces. The purpose of this article is to explain that the conflicting interests of those groups on such issues as written law or extraordinary taxation were the key to the conflict.

KEY WORDS: Frontier. State. Written law. Taxation. Ribagorza. Crown of Aragon. 13th century.

\section{INTRODUCCIÓN}

El concepto de «frontera» se ha convertido en las últimas décadas en un tema recurrente de la historiografía medieval, pero basta un vistazo a algunas obras colectivas relacionadas con esta cuestión para darse cuenta de la disparidad de realidades políticas y sociales que se designan con ese término, de donde se deriva una cierta ambigüedad tanto en el contenido semántico de la expresión como en los interrogantes históricos que lleva asociados ${ }^{1}$.

Escoger para el título de este artículo la idea de una «frontera» que se «construye» implica la elección de una determinada perspectiva de este fenómeno histórico. La palabra tiene dos principales acepciones, una con marcado carácter político, y otra esencialmente social ${ }^{2}$. Con la primera, designa las líneas -más o menos definidas- que separan los espacios en que intervienen las organizaciones sociales, una visión que concuerda con las percepciones geopolíticas del Estado-nación. La segunda se aplica a las zonas de contacto entre diferentes ámbitos políticos o culturales y, por extensión, a las peculiares sociedades que habitan estos espacios; esta concepción, formulada inicialmente por Frederik Turner para el Oeste norteamericano, ha sido la más empleada por los

1 Véase: BARTlett, Robert y MAcKay, Angus (eds.), Medieval frontier societies, Oxford, Clarendon, 1996; De Ayala Martínez, Carlos, Buresi, Pascal y Josserand, Philippe, Identidad y representación de la frontera en la España medieval (siglos XI-XIV): seminario celebrado en la Casa de Velázquez y la Universidad Autónoma de Madrid (14-15 de diciembre de 1998), Madrid, Casa de Velázquez, 2001; Studia Historica. Historia medieval, 23 (2005), número especial dedicado a «Fronteras y límites exteriores»; ABUlaFIA, David y BEREND, Nora (eds.), Medieval frontiers: concepts and practices, Aldershot, Ashgate, 2002.

2 Berend, Nora, «Preface», en Abulafia y Berend, Medieval frontiers, págs. X-XV; STOPANI, Antonio, La production des frontières. État et communautés en Toscane (XVI'-XVIII siècles), Roma, École Française de Rome, 2008, págs. 1-27. 
medievalistas para analizar la expansión de la cristiandad occidental a costa de las sociedades eslavas o islámicas ${ }^{3}$. Mientras la primera opción hace de la frontera un constructo político, administrativo o bélico, en la segunda define a las sociedades en contacto y mutua aculturación. Parece obvio que el caso aquí estudiado se inserta en la primera acepción.

La visión historicista del primer tipo de líneas fronterizas hace de ellas un escenario privilegiado de la acción de las naciones en forma de eventos armados o diplomáticos; sin embargo, más allá de las fluctuaciones políticas o militares, las explicaciones concretas e inteligibles de la presencia de estos límites suelen ser relegadas a un brumoso segundo plano, lo cual abre la puerta al recurso a justificaciones irracionales y remotas que actúan como si aquellos fuesen anteriores a las comunidades humanas, y estas se hubiesen moldeado a unas barreras preexistentes e invisibles. La visión opuesta, más habitual entre los historiadores, integra la construcción de las fronteras dentro del largo proceso de creación del Estado moderno, y niega que haya habido verdaderos confines políticos en la Edad Me$\mathrm{dia}^{4}$; ahora bien, esta interpretación tiende a concentrarse en el papel de las instituciones políticas, por lo que suele ignorar las relaciones entre frontera y sociedad, asunto que constituye el eje del presente artículo5.

Los límites entre los tres territorios peninsulares que componían la Corona de Aragón (Cataluña, Valencia y Aragón) proporcionan el ejemplo idóneo de la construcción de una frontera política. Al fin y al cabo, los orígenes y consolidación de esas divisorias no estuvieron marcados por ningún conflicto armado, sino que surgieron lentamente por el desarrollo divergente de cada territorio en aspectos como el derecho, la moneda, las instituciones o la lengua escrita, hasta cristalizar en nítidas líneas fronterizas, sin que, durante ese prolongado proceso, los reyes mostrasen especial preocupación en que los límites dentro de su propio reino siguiesen un trazado u otro. Este artículo pretende mostrar que, a diferencia de los soberanos, en la fijación de la frontera a su paso por Ribagorza, una comarca de dudoso encasillamiento previo, la sociedad local no fue una convidada de piedra, sino que interaccionó con la monarquía y con el naciente entramado institucional de Aragón y Cataluña para alcanzar la solución definitiva.

3 Una reflexión actualizada con amplia bibliografía sobre este modelo de frontera en: ToRRó, Josep, «Viure del botí. La frontera medieval com a parany historiogràfic», en Recerques, 43 (2001), págs. 5-32.

4 Véase por ejemplo: DupOnT-Ferrier, Gustave, «L'incertitude des limites territoriales en France du XIII ${ }^{\mathrm{e}}$ siècle au XVI $»$, en Comptes-rendus de l'Academie des Inscriptions et Belles-Lettres, París, 1942, págs. 62-77; o LADERo QuesADA, Miguel Ángel, «Sobre la evolución de las fronteras medievales hispánicas (siglos XI a XIV)», en AYALA, C. ET AL., Identidad y representación, págs. 5-49.

5 Los estudios de índole local son un buen método para observar de estos procesos; son interesantes, por ejemplo: PEYveL, Pierre, «Structures féodales et frontières médiévales: l'exemple de la zona de contact entre Forez et Bourbonais aux XIII ${ }^{e}$ et XIV ${ }^{e}$ siècles», en Le Moyen Âge, 93 (1987), págs. 51-83; CUNHA MARTINS, Rui, «La frontera medieval hispano-portuguesa: el punto de vista de la guerra», en VACA LORENZO, Ángel (coord.), La guerra en la historia, Salamanca, Universidad de Salamanca, 1999, págs. 95-114. 


\section{UN BREVE ESTADO DE LA CUESTIÓN}

El asunto del límite de Aragón con Cataluña ha sido abordado por autores de ambos territorios, aunque muchos de ellos están marcados por «apasionamientos deformantes» localistas, o incluso por la proyección hacia el pasado medieval de unas problemáticas políticas claramente contemporáneas. Por ello, parece conveniente comenzar con una rápida presentación de las respuestas que la historiografía ha ofrecido para los puntos en discusión durante los siglos XIII y XIV, es decir, las comarcas limítrofes de Ribagorza, La Litera, Fraga, Lérida y el Bajo Ebro.

Los cronistas del Quinientos, el fundamental Jerónimo Zurita y el ribagorzano Martín de Gurrea, aludieron en sus respectivos Anales a los enfrentamientos suscitados a la hora de integrar Ribagorza en Aragón o Cataluña ${ }^{6}$. El tema fue recogido por los historiadores de comienzos del siglo XX, aunque, al partir de postulados regionalistas, dieron lugar a dos versiones casi incompatibles de unos mismos hechos. Por ejemplo, Joaquim Miret i Sans asumió en 1918 que Ribagorza estuvo integrada en el Principado durante buena parte del siglo XIII, con una visión bastante razonada que se basaba en varios textos inéditos; sin embargo, un extenso artículo del zaragozano Andrés Giménez Soler le acusó de ocultar evidencias escritas contrarias a su tesis para terminar proclamando que el Cinca era «un río aragonés puro». Años después, M. ${ }^{a}$ Ángeles Masiá dejó en evidencia la parcialidad de Giménez Soler y presentó una perspectiva más o menos ecuánime y bien documentada, aunque dio por buenas varias afirmaciones erróneas, como que los dominios de Alfonso el Batallador terminaban en el Cinca o que no existía vinculación de «la Litera» con Aragón antes de 13007. De forma menos extensa, la cuestión fue tratada en síntesis históricas clásicas de ambos territorios: Ferrán Soldevila, en la Història de Catalunya, ve un sacrificio de «interessos molt legítims de Catalunya» en la incorporación de Ribagorza y «La Litera» a Aragón; Antonio Ubieto, por su parte, minimiza o ignora en la Historia de Aragón las vinculaciones de estas zonas limítrofes con el espacio catalán, lo que le permite resolver los problemas de forma tan categórica como poco convincente ${ }^{8}$.

Los trabajos de las últimas dos décadas han superado en buena medida estas disputas historiográficas teñidas de rencillas regionalistas. Flocel Sabaté y Enric

6 Zurita, Jerónimo (ed. Canellas López, Ángel), Anales de la Corona de Aragón, libro III, cap. XL, Zaragoza, Institución Fernando el Católico, 1998 [1562]. Los Anales de Ribagorza de Martín de Gurrea se conservan en BNE, ms. 2070.

7 Miret i SANS, Joaquim, Itinerari de Jaume I El Conqueridor, Barcelona, Institut d'Estudis Catalans, 1918; IDEM, «Documentos inéditos de los antiguos reyes de Aragón», en BABLB, 6 (1911), págs. 49-52; GIMÉNEZ SOLER, Andrés, «La frontera catalano-aragonesa», en II Congreso de Historia de la Corona de Aragón, Huesca, 1920, págs. 463-559; MASiá DEL Ros, M. ángeles, «La cuestión de los límites entre Aragón y Cataluña. Ribagorza y Fraga en tiempos de Jaime II», en $B A B L B, 22$ (1949), págs. 161-181.

8 SOlDEVILA, Ferrán, Història de Catalunya, Barcelona, Alpha, 1962, págs. 433-435; UBIETO ARTETA, Antonio, Historia de Aragón. La formación territorial, Zaragoza, Anúbar, 1981, págs. 313-354. 
Guinot han estudiado detalladamente la configuración territorial de Cataluña y Valencia, respectivamente, y merece la pena destacar el análisis que el primero de ellos hace de los problemas aquí afrontados ${ }^{9}$. Por lo que se refiere a los casos más concretos dentro del ámbito fronterizo, reviste especial interés un trabajo de Pascual Ortega en que interpreta la integración de Ascó, Horta y Miravet en Cataluña desde la perspectiva de un largo y áspero conflicto antiseñorial suscitado entre la orden del Hospital y sus vasallos. Del mismo modo, la peculiar situación de Fraga también ha sido examinada recientemente ${ }^{10}$.

Este panorama se debe cerrar lamentando que numerosas obras de divulgación sigan aferradas a posiciones superadas. Por la parte aragonesa, Manuel Iglesias considera que los testamentos de Jaime I anexionaron efectivamente Ribagorza al Principado, un hecho que tilda de «abuso histórico», «afán expansionista catalán» o «imprudente actitud»; y Agustín Ubieto, por su parte, reclama a los historiadores catalanes que muestren todos los testimonios y no solo los que sostienen su postura, pero él hace lo mismo para ignorar cualquier vinculación entre estas tierras y Cataluña, lo que le permite afirmar que «no cabe la más leve sospecha sobre el aragonesismo de estas tierras durante los siglos XI y XII» ${ }^{11}$. Al otro lado de la actual frontera, una obra de referencia como la Gran Enciclopèdia Catalana afirma — sin justificación- que incluso localidades tan occidentales como el valle de Bielsa formaron parte del Principado hasta 1305; la introducción histórica del tomo XVI de Catalunya Romàni$c a$, dedicado a la Ribagorza, señala que esta comarca se integraba en «una comunitat de cultura catalana a tots els nivells»; y una resumida historia de la Franja de Ponent de Joaquim Monclús habla de las «intromissions des d'Aragó» para sintetizar los vínculos que existían entre estas comarcas y dicho reino antes de $1300^{12}$.

La persistencia de estas visiones tendenciosas se explica por el indisimulado intento de ciertos sectores de la sociedad aragonesa y catalana de ensanchar la

9 SABAtÉ, Flocel, El territori de la Catalunya medieval. Percepció de l'espai i divisió territorial al llarg de l'Edat Mitjana, Barcelona, Fundació Salvador Vives, 1997, págs. 281-313; GuINOT RODRÍGUEZ, Enric, Els límits del regne: el procés de formació territorial del Pais Valenciá medieval (12381500), Valencia, Institución Alfonso el Magnánimo, 1995.

10 Ortega, Pascual, «Aragonesisme i conflicte ordes / vassalls a les comandes templeres i hospitaleres d'Ascó, Horta i Miravet (1250-1350)», en Anuario de Estudios Medievales, 25, 1 (1995), págs. 151-178; SALLERAS Clarió, Joaquín, Baronía de Fraga: su progresiva vinculación a Aragón (13871458), tesis leída en 2006. < http://www.tesisenxarxa.net/TDX-1015107-112946> (consulta: 17 de febrero de 2011).

11 Iglesias Costa, Manuel, Historia del condado de Ribagorza, Huesca, Instituto de Estudios Altoaragoneses, 2001, págs. 237-249; UBIETO ARTETA, Agustín, Aragón, comunidad histórica, Zaragoza, Gobierno de Aragón, 1991.

12 BoIX POCIELlO, Jordi, «La Ribagorça sota la monarquia catalano-aragonesa», en Catalunya Romànica XVI: Ribagorça, Barcelona, Fundació Enciclopèdia Catalana, 1996, págs. 44-45; Monclús I Esteban, Joaquim, «La Franja de Ponent. Dels orígens», en SistaC i VicĖN, Ramon (ed.), De fronteres i mil.lennis: la Franja, any 2001, Barcelona, Institut d'Estudis Catalans, 2003, págs. 75-80. 
brecha entre ambos territorios; la irracionalidad de algunas posturas planteadas en torno a la lengua o el patrimonio eclesiástico de las zonas limítrofes son un significativo (y preocupante) botón de muestra. Creo que la comprensión de los procesos históricos que han dado lugar al surgimiento de una frontera puede ser un método eficaz para relativizar las diferencias existentes entre quienes habitan a ambos costados de la misma, y que esto significa, en definitiva, un cuestionamiento de su legitimidad; por ello, considero que no solo es pertinente, sino también necesario, realizar un modesto esfuerzo para explicar racionalmente su génesis medieval.

\section{UNA ADSCRIPCIÓN TERRITORIAL AMBIGUA}

Si nos situamos en el contexto de los años centrales del siglo XIII, Ribagorza ocupaba una posición ambigua entre los dos grandes ámbitos políticos que - aún tenuemente - se distinguían dentro de los dominios de Jaime I. Por una parte, se había incorporado a la Corona en tanto que parte del reino de Aragón, como recordaba el siguiente texto de 1305:

«com reys antichs d'Arago, ans que fossen comtes de Barcelona, s'apellaven reys de Sobrarp e de Ribagorça» 13 .

Y en el sentido contrario, existían estrechos lazos entre este territorio y los condados orientales, especialmente intensos en el caso del vecino Pallars: en el transcurso del siglo XII los condes del Pallars Jussá lograron el dominio de casi todo el espacio de nuestro estudio, llegando a intitularse «condes de Ribagorza», momento al que debe de remontarse la instalación en Ribagorza de varios linajes nobiliarios pallareses (Vilamur, Mitad, etc.); de forma más explícita, en 1214, durante la minoría de Jaime I, una asamblea de magnates catalanes determinó que el límite de Cataluña, a efectos de la recaudación del bovaje, se situaba en el río Cinca ${ }^{14}$.

Hasta los últimos años del Doscientos no surgió el problema de la adscripción catalana o aragonesa de Ribagorza, ya que, antes de ese momento, la articulación política y definición territorial de ambas entidades seguía siendo débil ${ }^{15}$. Esta relativa fluidez de los espacios gubernativos — común al resto de

13 ACA, reg. 236, f. 11v (publicado en: MireT, «Documentos inéditos»).

14 BARAut, Cebrià, «Els documents dels anys 1101-1150 de l'Arxiu Capitular de la Seu d'Urgell», en Urgellia, 9 (1988-1989), pág. 286: Arnallus Miro, comes in Paliares et in Ripacurcia (1141); CDSV, doc. 219: Arnal Mir, comes Ripacurcie (1174). La asamblea de 1214, en Cortes de los antiguos Reinos de Aragón y de Valencia y Principado de Cataluña. Tomo 1. Primera parte, Cortes de Cataluña (comprende desde el año 1064 al 1327), Madrid, Real Academia de la Historia, 1896, pág. 91.

15 Sobre la formación de estos ámbitos políticos: Sesma MuÑOZ, José Ángel, La Corona de Aragón. Una introducción crítica, Zaragoza, Caja de Ahorros Inmaculada, 2000, págs. 51-75; BIssON, 
Europa- comenzó a cambiar en los años centrales del siglo XIII, cuando Jaime I redactó varios testamentos que preveían el reparto de la Corona entre sus hijos, obligando a establecer el trazado preciso de las sucesivas divisiones previstas. Tras una larga discusión que conocemos exclusivamente a través de las referencias de Jerónimo Zurita, en 1251 se decidió asimilar la comarca a Cataluña a efectos de esta partición, lo que a veces se ha interpretado como una confirmación de la catalanidad de Ribagorza ${ }^{16}$. Pero, aunque comprensiblemente este asunto haya concentrado la atención de los investigadores que han abordado la frontera catalanoaragonesa, la realidad es que ninguno de los repartos se llevó a la práctica, puesto que en 1262 un nuevo testamento invalidó a los anteriores, y redujo la fragmentación de la Corona a la entrega de reino de Mallorca al infante Jaime.

Los documentos de los últimos años del Conquistador muestran que aquellas disquisiciones testamentarias no alteraron la indefinición territorial de Ribagorza. Prueba de ello es que la moneda usual seguía siendo la jaquesa, el obispo era leridano o urgelés, o que el oficial real que gobernaba la zona utilizaba indistintamente el título aragonés de sobrejuntero y el catalán de veguer mientras se hacía cargo de un distrito que también abarcaba Sobrarbe y Pallars. La manifestación más clara de este «dualismo» era la convivencia de los Fueros y los Usatges, códigos legales cristalizados a mediados del siglo XIII, que se ejemplifica bastante bien en un mandato que Pedro III envió al sobrejuntero en 1281:

«quod in causis militum [...] exerceat Usaticum Barchinone et paces et treugas Catalonie, et in causis rusticorum Forum Aragonum et formam pacis Aragonum»17.

El control que los milites — esto es, la élite laica y militarizada - ejercían sobre el territorio ribagorzano se basaba en la posesión de feudos o castellanías, instituciones con las que monarcas o grandes señores atribuían el dominio directo de sus castillos a nobles de menor categoría, generalmente de origen local, que recibían como recompensa una dotación de bienes y rentas ${ }^{18}$. Este modo de proceder comenzó a difundirse por los condados de la órbita de Barcelona a comien-

Thomas, «L'essor de Catalogne: identité, pouvoir et idéologie dans une societé du XII siècle», en Annales ESC, 39 (1984), págs. 454-479; SABATÉ, El territori.

16 ZURITA, Anales, libro III, caps. 40, 43, 46 y 62.

17 ACA, reg. 49, f. 49r. El texto es algo confuso, pero la orden parece afectar al conjunto de la sobrejuntería.

18 Una descripción bastante profunda de la génesis y característica de esta institución en la zona catalana en: BONNASSIE, Pierre, Cataluña mil años atrás (siglos X-XI), Barcelona, Península, 1988, págs. 351-381. Respecto a Aragón, véase: LACARRA DE Miguel, José María, "Honores” et "tenencias" en Aragon (XI siècle)", en Les structures sociales de l'Aquitaine, du Languedoc et de l'Espagne au premier âge féodal, París, CNRS, 1969, págs. 143-186. 
zos del XI y llegó a ser un rasgo definitorio de la organización política de esa región, como refleja la preocupación de Alfonso II por compilar la documentación referida a los feudos en el cartulario llamado Liber Feudorum para reafirmar su posición en la cumbre de esta red de relaciones vasalláticas ${ }^{19}$. En Aragón estas funciones fueron desempeñadas inicialmente por tenentes, y desde 1200, aproximadamente, por alcaides, cargos bastante similares a los feudatarios, aunque presentaban ciertos rasgos distintivos, sobre todo en lo referido a su transmisión hereditaria. Los feudos se detectan esporádicamente en Ribagorza desde fechas tempranas, pero hasta el dominio pallarés durante la segunda mitad del siglo XII no se difundieron de una manera comparable a la catalana ${ }^{20}$. Los Usatges de Barcelona contemplaban la regulación de todas las eventualidades relacionadas con esta institución, así que su aplicación se extendía a todos aquellos lugares de la Corona de Aragón donde existían feudatarios. En definitiva, se puede afirmar que el empleo de los Usatges catalanes en Ribagorza estaba ligado a la nobleza local, ya que esta fundamentaba su autoridad en un tipo de concesión feudal regulada por ese código.

Tal como señala el citado mandato de Pedro III, en la segunda mitad del siglo XIII los «rústicos» ribagorzanos solían regirse por la foralidad aragone$\mathrm{sa}^{21}$. Hasta los años centrales de aquella centuria menudean las menciones al derecho consuetudinario local (ad bonam consuetudinem terre), junto a otras expresiones como per Costum de Barcelona vel per Fuero de Aragone que muestran, en primer lugar, que los notarios y juristas de la zona ya recurrían a estos códigos como referencias legales cultas y, segundo, que persistía una cierta imprecisión a la hora de decantarse por uno de ellos $^{22}$. En adelante, tal vez a raíz de la compilación de Huesca, la legislación de Aragón fue homogeneizando los usos locales: consecuencia de ello podría ser la tardía, pero rápida, introducción en la zona de elementos jurídicos típicamente aragoneses, como las infanzonías, las alifaras o los vocablos «jurado» y «adelantado» para los magistrados municipales $^{23}$. Los concejos debieron de asumir de manera generalizada esta forali-

19 Kosto, Adam J., "The Liber Feudorum maior of the counts of Barcelona: the cartulary as an expression of power», en Journal of Medieval History, 27 (2001), págs. 1-22.

20 Un temprano ejemplo de juramento feudovasallático en Ribagorza, en: MARTíN DuQUE, Ángel J., «Graus: un señorío feudal aragonés en el siglo XII», en Hispania, 18 (1958), págs. 159-180.

21 Se debe citar como precedente que, al parecer, en 1158 Ramón Berenguer IV otorgó a los habitantes de Lascuarre los mismos fueros que disfrutaba la ciudad de Jaca: Arco, Ricardo del, «Escudos heráldicos de ciudades y villas de Aragón», en Argensola, 18 (1954), pág. 124.

22 Algunas referencias a la «buena costumbre de la tierra» en CDG, docs. 27, 28 y 29 (1187), etc. En ocasiones la oposición del fuero y el costum se refuerza por el empleo del término acorde con la evolución fonética del aragonés y del catalán, respectivamente, para designar a cada una de estas tradiciones jurídicas, en CDG, docs. 54 (1225) o 61 (1252)

23 Las «alifaras» eran comidas campesinas que reunían a los implicados en diferentes actos jurídicos con la finalidad de ratificar socialmente estas transacciones (LALIENA CORBERA, Carlos, "Sicut ritum est in terra aragonensis": comidas rituales y formas de solidaridad campesina en el siglo XI», en Col.loqui d'Història de l'Alimentació a la Corona d'Aragó, vol. 2, Lérida, Institut d'Estudis 
dad: un privilegio real de 1276 confirmaba su vigencia en Benabarre, mientras que, en 1289, el abad de San Victorián se comprometió a que no se aplicase en Graus ninguna ley que no fuese la aragonesa ${ }^{24}$. Al igual que los rústicos, los infanzones (estatuto propio de campesinos ennoblecidos, desvinculado de los feudos) debieron de ser inequívocos usuarios de esta foralidad, puesto que de ella se derivaba el reconocimiento de su condición. En 1261 se menciona por primera vez el Justicia de Ribagorza, oficial real asentado en Graus que tenía competencias judiciales sobre universis infançonibus et aliis universis qui babent per Forum Aragonum judicari25.

En resumen, la ambigüedad del encuadramiento del territorio ribagorzano en uno de los dos grandes ámbitos políticos que lo rodeaban se manifestaba en la vigencia simultánea de sus respectivos sistemas legales y judiciales, cada uno de los cuales era utilizado preferentemente por un grupo social diferente. Por ello, es comprensible que las posteriores reivindicaciones para que primase la opción catalana o la aragonesa se cruzasen con los intereses de esos colectivos.

\section{LA UNIÓN ARAGONESA Y LA CUESTIÓN DE RIBAGORZA}

En el transcurso de la primera Unión de Aragón (1283-1290) se planteó por primera vez con claridad el problema de la adscripción de Ribagorza: a partir de este momento, su basculamiento hacia levante o poniente siguió el ritmo del conflicto ${ }^{26}$. Se ha propuesto, al respecto, la existencia de una reivindi-

Ilerdencs, 1995, págs. 665-691); aunque Ribagorza quedase inicialmente fuera de las regiones en donde se celebraban las alifaras, estas tuvieron una gran difusión por la comarca en el siglo XIII (véase, por ejemplo: ACL, FR, perg. 4, 55, 89, 967, etc.). A diferencia de Aragón, en Ribagorza no se utilizó el término «infanzón» antes de mitad del siglo XIII y, aún después, no alcanzó la difusión que tuvo en comarcas más occidentales (véase sobre esta categoría social: LALIENA CORBERA, Carlos, «État, justice et servitude en Aragon au $\mathrm{XIV}^{\mathrm{e}}$ siècle», en Histoire et Sociétés Rurales, $30\left[2^{\circ}\right.$ semestre de 2008], págs. 7-30). Sobre el empleo de los términos «jurado» o «adelantado», véase a título comparativo una geografía del léxico que se empleaba en Cataluña para esta institución en: SABATÉ, El territori, págs. 412-413.

24 Bofarull y Mascaró, Próspero, Colección de documentos inéditos del Archivo General de la Corona de Aragón, t. VIII, Barcelona, Imprenta del Archivo, 1851, págs. 146-148; CDG, doc. 68.

25 ACA, reg. 11, f. 210r (1261); 64, f. 91r (1286).

26 Las asambleas de Calatayud, Huesca y Ejea en 1265 fueron un precedente de la Unión de 1283, aunque en aquellas el predominio aristocrático fue aún más acusado; entre otras cosas, los ricoshombres aragoneses señalaron entonces que Ribagorça es del «regno d'Aragon et ha Fueros d'Aragon, et deçimos que en muytas cosas los tole el rey los Foros d'Aragon» (CANELlas LópeZ, Ángel, «Fuentes de Zurita: Anales, III, 66-67. Las Asambleas de Calatayud, Huesca y Ejea en 1265», en Revista de Historia Jerónimo Zurita, 31-32 (1978), págs. 7-41). Esta queja debe de estar vinculada a los intereses concretos de la familia Entenza en el reparto de caballerías, y, de manera más general, a la coexistencia del derecho aragonés y catalán en la zona. En cualquier caso, no hace más que retrotraer en dos décadas las mismas cuestiones que se jugaron a partir de 1283 , por lo que no me detendré en el análisis específico de este escueto texto. 
cación «popular» y «nacionalista» tanto dentro de Aragón como de Cataluña sobre este área limítrofe, a pesar del carácter resbaladizo e indemostrable de tal afirmación; en el mismo sentido, se ha alegado que la Unión no contaba con la colaboración de ningún ribagorzano y que, por ello, no hizo más que arrogarse la representación de la comarca sin tener derecho alguno a ello 27 . Por el contrario, creo que el análisis de las peculiares circunstancias de la zona y de los intereses de sus componentes sociales apuntan a una implicación bastante activa y consciente. De hecho, sabemos que la villa de Capella envió algún representante, que Benabarre cum universorum locorum Ripacurcie qui sunt de Unitate Aragonum contribuyeron económicamente, o que varias familias nobles locales como los Benavent, los Peralta o los Entenza intervinieron continuadamente ${ }^{28}$.

En el contexto de la Unión, se presentaron ante la monarquía tres series de quejas relativas a Ribagorza, que permiten conocer las expectativas sociales de quienes apoyaban el movimiento ${ }^{29}$. La mayoría de las protestas respondían a los intereses de las comunidades rurales en tres aspectos fundamentales ${ }^{30}$. Primero, la autonomía de los concejos para gestionar diversas competencias, como el nombramiento de notarios y corredores públicos. Segundo, la moderación de la presión fiscal regia, que, desde mitad del siglo XIII y, en particular desde el acceso de Pedro III al trono, había sufrido un fuerte incremento: el descontento se refería al bovaje de 1279 (del que decían estar exentos en tanto que aragoneses), a la gabela sobre la sal de 1281, a las elevadas tasas que percibían los jueces reales y sobrejunteros por el ejercicio de su oficio, y al salvoconducto que pagaban los ganados trashumantes en sus trayectos estacionales. Y tercero, reclamaron que les fuesen correctamente observados los Fueros, que se mantuviese el cargo de Justicia de Graus y que se les permitiera apelar las sentencias ante otros tribunales aragoneses. Unas quejas, en definitiva, coincidentes con lo que habían expresado la mayoría de los concejos de Aragón (salvando lo referido a la aplicación de los Fueros, que es la particularidad local): aunque desconozcamos los cauces de la representación de los rústicos ribagorzanos, está claro que, a través de ellos, plantearon unas reivindicaciones concretas y realistas.

Los intereses de la familia Entenza, de un color social totalmente distinto, se evidencian en otra de las reclamaciones presentadas en octubre de 1283:

27 SABATÉ, El territori, pág. 294: «una noblesa aragonesa fortament encrespada contra el monarca [...] pot assumir la defensa de la identitat aragonesa de la Ribagorça com a manera de pressió contra el monarca i com a via de contactar amb les línies d'identitat col.lectiva que es van estenent a Aragó»; GoNZÁLEZ, Las Uniones, vol. 1, pág. 462: «Aragón proclama su unidad esencial con Ribagorza», «los nobles aragoneses, pues, se arrogan la representación de unos territorios cuyo carácter en aquel momento es decididamente mixto [...] como Ribagorza».

28 Castillón CoRTADA, Francisco, «Documentos de Capella (Huesca) en el manuscrito núm. 729 de la Biblioteca de Cataluña (Barcelona)», en Argensola, 89 (1980), pág. 216; ACA, reg. 88, f. 8v.

29 GonZÁlez, Las Uniones, vol. 2, págs. 29-32, 57 y 86-87.

30 En torno a las razones de la implicación de las comunidades locales en el movimiento unionista, véase: LALIENA CORBERA, Carlos, «La adhesión de las ciudades a la Unión: poder real y conflictividad real en Aragón a fines del XIII», en Aragón en la Edad Media, 8 (1989), págs. 399-413. 
«solia seer Ribagorça en caverias a los richosomnes asi como es Aragon, e agora el seynor rey tienesela, que non la da»31.

Frente al régimen catalán de los feudos, los nobles aragoneses eran recompensados por sus servicios a la monarquía mediante caballerías, esto es, porciones de 500 sueldos salidas de los derechos del rey que solían ser copadas por un selecto grupo de ricoshombres que, después, las repartían entre sus respectivas clientelas. Bernardo Guillermo de Entenza aspiraba a que el monarca procediese con las rentas regias de Ribagorza como se hacía en Aragón, ya que esto le permitiría hacerse con buena parte de los ingresos ordinarios del rey. Pedro III accedió a esta petición en primavera de 1284, y entregó al aristócrata doce caballerías sobre las pechas ribagorzanas, es decir, 6.000 sueldos anuales ${ }^{32}$. El peso que los Entenza pretendían alcanzar en Ribagorza se observa igualmente en el hecho de que, cuando los unionistas nombraron un consejo real, les encomendaron el oficio de sobrejuntero en este territorio, y que a Gombaldo hijo de Bernardo Guillermo- se le adjudicase el informal título de tenient la terra de Ribagorça ${ }^{33}$. Aparte de esa familia, otros nobles autóctonos se contaban entre los partidarios de la Unión: la toma de posición de Bernardo de Malleón, castellán de Benasque, podría derivar de su enfrentamiento con el noble pallarés Acardo de Mur por el dominio de algunos castillos en el valle del Noguera Ribagorzana, un asunto en el que la monarquía apoyó al segundo ${ }^{34}$; Gombaldo de Benavent, por su parte, tenía suficientes intereses y vínculos en Aragón para explicar su alineamiento con la gran nobleza aragonesa, pese a que la sede de su linaje estuviese en la aldea ribagorzana de donde tomó el apellido.

Las comunidades rurales y algunas grandes casas aristocráticas intervinieron en la Unión movidas por pretensiones muy distintas pero convergentes en la reivindicación de ciertas ventajas inherentes a la condición jurídica de los aragoneses. Las oscilaciones de este territorio en su alineamiento con los unionistas o con la monarquía hacen sospechar que también había sólidos partidarios de la segunda opción, aunque los documentos apenas aporten datos al respecto. Solo se pueden citar los destinatarios de un mandato de Alfonso III en 1287 para proteger al unionista Gombaldo de Benavent de los ataques del bando contrario, a los cuales el contexto identifica como enemigos de la Unión: Bernat Roger de Erill, Guillem de Castellvell, Ferrer de Ape y Ramón de Agui$\operatorname{lar}^{35}$. Aunque sea arriesgado sacar conclusiones de una muestra tan reducida,

31 GonZÁLEZ, Las Uniones, vol. 2, pág. 29.

32 ACA, reg. 45, f. 42v.

33 GONZÁLEZ, Las uniones, vol. 2, pág. 276.

34 Ibidem, vol. 2, págs. 226-227.

35 ACA, reg. 74, f. 3v. Bernat Roger era señor de la baronía de Erill, Guillem de Castellvell pertenecía a un linaje ampliamente documentado en la comarca emparentado con los anteriores, y la familia Ape se menciona en varias ocasiones en las convocatorias del rey a los feudatarios de Pallars para prestar el servicio militar (GONZÁLEZ, Las uniones, vol. 2, págs. 175 y 528). De Ramón 
parece que los oponentes de la Unión procedían de nobleza feudal pallaresa, plenamente integrada en los círculos aristocráticos catalanes, cuyo ámbito de influencia abarcaba buena parte de Ribagorza: los Castellvell ejercían la castellanía de Pueyo de Ésera en nombre del también pallarés linaje de Vilamur; los Erill tenían el feudo de Capella y habían dado lugar a las estirpes de Espés y Fantova $^{36}$, etc. El recurso al mero determinismo geográfico para explicar estos posicionamientos puede generar explicaciones simplistas e insuficientes; no obstante, creo que se puede admitir que, en esta zona limítrofe, la orientación de los intereses familiares y clientelares supuso un factor de división interna a tener en cuenta.

Pedro III asumió inicialmente el grueso de las reivindicaciones unionistas mediante la firma del Privilegio General, lo cual supuso la aceptación de todas las peticiones ribagorzanas (incluida la dilapidación de las bases fiscales del monarca a favor de los Entenza), pero esto cambió drásticamente tras el acceso de Alfonso III al trono, a finales de 1285. En febrero de 1286 se otorgaron a Jaime Pérez, hijo bastardo de Pedro III, las caballerías de los Entenza, en un acto que parece ser tanto un castigo a esta familia como un intento de atraerse el favor de un infante que dudaba en su apoyo a la causa rebelde ${ }^{37}$. El sobrejuntero Ramón de Molina fue confirmado inicialmente en su cargo en el mismo mes de febrero, pero en marzo se tuvo que enfrentar con el unionista Pedro Maza de Lascellas, que pretendía ejercer estas funciones contra la voluntad regia; y finalmente en abril el monarca emitió una orden en la que señalaba que Ribagorza pertenecía a la «Procuración» de Cataluña y que, por tanto, la provisión del oficio correspondía al procurador que actuaba en aquel momento, el conde pallarés Arnau Roger, el cual designó como nuevo sobrejuntero o veguer a Bort de Pallars, miembro de su linaje. Ante esta última decisión, algunos nobles locales como Guillermo de Peralta y Gombaldo de Benavent se negaron a reconocerlo como tal, alegando que Ribagorza pertenecía ad Procuracionem Aragonum et esse sub Foro Aragonum, y trataron de usurpar el cargo pese a las repetidas órdenes reales para que renunciasen a tal pretensión. Además, Alfonso III nombró a otro pallarés, Beltrán de Tremp, como Justicia en Graus para las personas que se rigiesen por los Fueros, y se adoptó una novedosa actitud restrictiva ante los infanzones que no hubiesen demostrado su condición ${ }^{38}$.

En estas complicadas circunstancias se deben entender también las graves resistencias frente a los recaudadores reales de 1287:

\footnotetext{
de Aguilar tenemos menos datos, pero sabemos que en 1292 tenía propiedades en torno a Arén (ACA, reg. 93, f. 231v).

36 Ostos SAlCEDo, Pilar, «Documentación del Vizcondado de Vilamur en el archivo ducal de Medinaceli», en Historia, instituciones, documentos, 8 (1981), docs. 35 y 36; MIRET I SANS, Joaquim, «La casa senyorial d'Erill», en Anuari Heraldic, 1917, págs. 131-157.

37 ACA, reg. 65, f. 46v.

38 Ibidem, reg. 64, f. 91r; 65, ff. 37v y 87r; 66, f. 34r, 121r, 159v y 251v; 70, f. 76v.
} 
«homines Benavarre et quorumdam aliorum locorum Rippacurcie abstulerunt per violenciam collectoribus dictarum cenarum pign[or]am que dictis hominibus fecerant racione dictarum cenarum, vilipendendo et percutendo eosdem»39.

La argumentación que esgrimieron los vecinos de algunos pueblos demuestra que esta insumisión estaba relacionada con el conflicto en curso: afirmaron que habían pagado previamente el impuesto a los Entenza por razón de sus caballerías (pese a que, como hemos dicho, Alfonso III las había reasignado) y que, por ello, no iban a contribuir en una segunda ocasión. El carácter político de la documentación cancilleresca dificulta conocer el ambiente social que acompañaba a todos estos acontecimientos, aunque la escueta mención al incendio de Capella a manos de los hombres de pueblos vecinos, en el verano de 1287, nos recuerda que la violencia inherente a un conflicto como el aragonés podía alcanzar a todos los estratos de la población ${ }^{40}$.

Un nuevo giro se produjo en 1288, después de que el rey claudicase ante las peticiones unionistas: desembargó los bienes de Gombaldo de Entenza y lo nombró sobrejuntero de Ribagorza a propuesta de la Unión ${ }^{41}$. Es representativo de esta coyuntura de aparente triunfo de la opción aragonesa el privilegio que el abad de San Victorián otorgó a los vecinos de Graus en 1289 para la meliorationi ac reparacioni ipsius ville que destrucciones, guerras et mala et dampna plurima sustinuit: implicaba el incremento de la autonomía municipal, la supresión de numerosas cargas serviles y, lo que es más relevante para este trabajo, una contundente confirmación de la vigencia de la foralidad aragonesa ${ }^{42}$.

La admisión por el monarca de buena parte de las peticiones y la radicalización de algunos nobles en sus exigencias limitaron la base social de la Unión, lo que permitió a Alfonso III reconducir la situación a partir de 1290. La más que previsible consecuencia en la zona fue la destitución de Gombaldo de Entenza de la sobrejuntería a comienzo de ese año —que no se logró sin su resistencia- para nombrar en su lugar a Sancho Ortiz de Pisa, un aragonés favorable al rey ${ }^{43}$. Tras el acceso al trono de Jaime II, este reunió unas Cortes en Zaragoza en septiembre de 1291 a las que fueron convocados los representantes de los concejos de Ribagorza y Pallars ${ }^{44}$; los súbditos juraron fidelidad al rey y este se comprometió a observar:

39 Ibidem, reg. 70. f. 146r.

40 Ibidem, reg. 70, ff. 105v y 190v.

41 Ibidem, reg. 74, f. 54r; GONZÁLEZ, Las Uniones, vol. 2, pág. 274.

42 CDG, doc. 68. En él se describen algunas mejoras que esta foralidad aportaba a los vecinos de la localidad, como la posibilidad de alegar en sus juicios ante otros tribunales aragoneses o la gestión de la primicia por el concejo como solía hacerse en Aragón.

43 ACA, reg. 81, f. 110r.

44 GonZÁLEZ, Las uniones, vol. 2, págs. 421-422: «universitatibus villarum et locorum Ribacurcia, universitatibus villarum et locorum Pallares»; también aparecen los feudatarios de ambos territorios. Pese a haber sido convocados, los pallareses no figuran en la lista de asistentes al acto. 
«furs et privilegis generals, uses et costumes d'Arago, de Terol, de Ribagorça e als infançons del regne de Valencia fur d'Arago a quil' querria»45.

Una expresión estereotipada que suponía un cierto reconocimiento de las reivindicaciones de la Unión; también acudieron al acto varios nobles ribagorzanos para prestar homenaje por sus feudos. Sin embargo, en la posterior reunión de las primeras Cortes catalanas del mismo monarca, a comienzos de 1292, se acordaron dos capítulos sobre el vicarius de Ripacurcia, con los que se garantizaba la aplicación de los Fueros o Costumbres en las localidades en donde estuviesen vigentes ${ }^{46}$.

El prolongado conflicto unionista había concluido para Ribagorza con un cierto retorno a la ambivalencia previa a su estallido en 1283, aunque el encasillamiento administrativo dentro de Cataluña era más evidente: por ejemplo, la vacilación entre «veguer» $\mathrm{y}$ «sobrejuntero» fue sustituida por el predominio del primer término entre 1292 y 1300 , periodo en que todos los que desempeñaron el cargo fueron catalanes. Ahora bien, la irrupción de la problemática fiscal durante esos mismos años iba a ocasionar el último y definitivo vaivén de Ribagorza entre Cataluña y Aragón.

\section{EL AUGE DE LA FISCALIDAD}

Durante la segunda mitad del siglo XIII se verifica en buena parte de los espacios políticos europeos un gran desarrollo de las estructuras estatales, que influyeron de un modo cada vez más intenso e intrusivo en la vida social: la aludida creación y generalización de códigos legales cultos como los Fueros de Aragón es una faceta de este proceso, pero la que probablemente afectó más directamente a casi toda la población fue el auge de la fiscalidad ${ }^{47}$. El constante incremento de las exigencias reales en la Corona de Aragón arrancó a mitad de la centuria, se aceleró tras el acceso al trono de Pedro III, como consecuencia de la conquista de Sicilia, y fue uno de los motivos del estallido de la Unión.

45 Ibidem, vol. 2, pág. 425.

46 Cortes de los antiguos Reinos de Aragón, pág. 162, artículos 37 y 38.

47 Con carácter general, véase: SESMA MUÑOZ, José Ángel, «Las transformaciones de la fiscalidad real en la Baja Edad Media», en XV Congreso de Historia de la Corona de Aragón. El poder real en la Corona de Aragón, t. I, vol. I, Zaragoza, Gobierno de Aragón, 1994, págs. 231-292; SÁNCHEZ MartíneZ, Manuel, El naixement de la fiscalitat d'Estat a Catalunya (segles XII-XIV), Barcelona, Eumo, 1995; WICKHAM, Christopher, «Lineages of western european taxation (1000-1200)», en SÁnCHEZ MARTínez, Manuel y Furió, Antoni (coord.), Col.loqui Corona, municipis i fiscalitat a la baixa Edat Mitjana, Lérida, Institut d'Estudis Ilerdencs, 1997, págs. 25-42. Respecto a las consecuencias sociales de la fiscalidad, resulta de gran interés LALIENA CorBERA, Carlos, «El impacto del impuesto sobre las economías campesinas de Aragón en vísperas de la Unión (12771283)», en Monnaie, crédit et fiscalité dans le monde rural. La conjoncture de 1300 en Méditerranée occidentale (texto en vías de publicación que me ha sido amablemente proporcionado por su autor). 
Este movimiento, sumado a algunas reclamaciones parecidas en Cataluña y Valencia, puso en evidencia la necesidad de contar con las fuerzas sociales de los países de la Corona para implantar unos impuestos que se justificaban en su utilidad pública; de este modo, el desarrollo del fisco regio fue acompañado de la consolidación de las Cortes como organismo representativo de las elites del país, y esto se evidenció en que, a partir de estos años, las exigencias extraordinarias de los reyes aragoneses fueron consensuadas en estas reuniones estamentales. En cierta manera, tales transformaciones supusieron que Aragón y Cataluña dejasen de ser abstracciones territoriales y políticas para ascender al rango de sujetos jurídicos dotados de capacidad de interlocución a través de sus elites aristocráticas y urbanas; en consecuencia, las fronteras que los separaban adquirieron una renovada importancia, pues se convirtieron en el límite geográfico de las competencias y decisiones de cada una de estas asambleas ${ }^{48}$.

El problema del encuadramiento territorial de Ribagorza, que hasta ahora tenía repercusión reducida y que en buena medida se había superado mediante el ecléctico criterio de asumir la aplicación del derecho habitual en cada localidad, alcanzó una nueva dimensión con los progresos de la demanda fiscal impulsados por Jaime II: en el periodo 1290-1300 se pretendió recaudar en la zona la totalidad de los impuestos aprobados tanto por Cataluña como por Aragón. Por ejemplo, las aludidas Cortes de Zaragoza de 1291 decidieron recaudar un auxilio para el rey, en el que los ribagorzanos debían contribuir con los aragoneses, mientras que las inmediatamente posteriores Cortes catalanas acordaron una sisa a Cincha usque ad collum de Paniçars, es decir, en todo el Principado, incluyendo en él Ribagorza ${ }^{49}$. Finalmente, los ribagorzanos solo debieron colaborar en la sisa catalana, no sin numerosas resistencias frente a los oficiales reales; ahora bien, esta anómala situación había mostrado que la ambigua delimitación territorial planteaba problemas tanto al monarca como a sus súbditos, una evidencia que acabaría por forzar la resolución de la disyuntiva.

Las reticencias de los campesinos frente a los recaudadores del rey fueron una constante en las exigencias fiscales en toda la Corona de Aragón. Sin embargo, la resistencia de los concejos ribagorzanos ante los subsidios catalanes reviste un carácter diferente, por su regularidad y por la concreción de sus objetivos, y esto lleva a preguntarse por qué las comunidades tomaron partido por la fiscalidad del reino de Aragón, siendo que el importe de las exacciones en uno y otro territorio parece ser muy similar. Hay varias posibles respuestas, compatibles entre sí: que los contribuyentes eran los mismos campesinos que se regían por los Fueros; que las cargas aragonesas eran percibidas como menos agraviantes que las sisas catalanas; que una parte significativa de la población,

48 GonZÁlez ANTÓn, Luis, «Las Cortes aragonesas en el reinado de Jaime II», en Anuario de Historia del Derecho Español, 47 (1977), págs. 523-682.

${ }_{49}$ ACA, reg. 85, f. $10 v$; 306 , ff. $10 v, 24 v, 39 v$ y 51 r. No es razonable pensar que se recaudasen ambos subsidios, pero en todo caso es evidente que la petición fue enviada desde ambas partes. 
revestida de las exenciones propias de los infanzones, eludía el pago de los tributos aragoneses; que se confiaba más en las vías de representación y apelación usuales en Aragón; etc. En todo caso, existía un ambiente que veía con mejores ojos la vinculación fiscal con el espacio aragonés; un posible eco de esa opinión es que, en 1297, el abad de San Victorián ofreció la franqueza de todas las cargas a quibus infanciones Aragonie sunt libere como reclamo para atraer pobladores a Campo, una villa que había fundado en Ribagorza ${ }^{50}$.

Aunque las cargas extraordinarias eran el objeto central de la discusión, se sabe que también las rentas ordinarias se intentaron equiparar a los procedimientos y ritmos comunes en Aragón. Un curioso informe redactado en torno a 1295 por Guillem Cabrit, recaudador real en Ribagorza, describe las numerosas trabas que los concejos interponían a su labor. Entre otros impedimentos, muchos pueblos se negaban a abonar la pecha tro que pagas Arago et Tamarit et Sent Steven, siendo que, hasta entonces, la gestión de este impuesto en Pallars y Ribagorza se había hecho separadamente del resto de la Corona. El escrito finaliza con una expresiva advertencia que previene al canciller de la actitud de los vecinos de la comarca ante los oficiales reales:

«[...] no creatz nuyll hom de Ribagossa de ço que us diguen, que vergoya an totz tems de dir veritat, et preense de monsonges»s1.

El ciclo fiscal iniciado tras la muerte de Jaime I fue decisivo, especialmente a través de uno de sus principales componentes: el bovaje solicitado en Cataluña cada vez que advenía un nuevo rey. Pedro III había aceptado en 1283 que el bovaje que había obligado a pagar a los habitantes de la comarca en los años precedentes era ilegítimo, «seyendo Ribagorza del regno de Aragon, non deviendo aquel pagar», una reivindicación que se plasmó en el Privilegio General $^{52}$. Sin embargo, cuando Jaime II procedió a cobrar este impuesto en Cataluña con motivo de su entronización, en 1297, se enviaron órdenes a decenas

50 TOMÁs FACI, Guillermo, «La carta de población de Campo (Ribagorza, Aragón) en 1297, ejemplo de transformación del paisaje humano pirenaico», en BARRAQUÉ, Jean-Pierre y SÉNAC, Philippe (ed.), Habitats et peuplement dans les Pyrénées au Moyen Âge et à l'époque moderne, Toulouse, FRAMESPA, 2009, págs. 125-142.

51 Ibidem, cartas reales de Jaime II, caja 126, 1939 («no creáis a ningún hombre de Ribagorza de lo que os diga, que les da vergüenza decir la verdad y se precian de ser mentirosos»).

52 GonzÁlez, Las Uniones, pág. 29. Sobre el bovaje en Cataluña, véase: OrTi Gost, Pere, «La primera articulación del estado feudal en Cataluña a través de un impuesto: el bovaje (ss. XIIXIII)», en Hispania, 209 (1991), págs. 967-998; LóPEZ PIZCUETA, Tomás, «Sobre la percepción del "bovatge" en el siglo XIV: una aportación al tema de la tasación directa en la Cataluña bajomedieval», en SÁNCHEZ MARTínEZ, Manuel, Estudios sobre renta, fiscalidad y finanzas en la Cataluña bajomedieval, Barcelona, CSIC, 1993, págs. 335-347. A lo largo del siglo XIII se produce una divergencia entre Aragón y Cataluña al respecto: en el reino aragonés se implantó el monedaje, mientras que en el principado se consolidó el bovaje, en ambos casos como impuestos con un fuerte componente de reconocimiento de la soberanía real. 
de localidades aragonesas emplazadas al este del Cinca y, mientras bastantes de las sobrarbesas evitaron el pago, las de Ribagorza fueron obligadas a hacerlo del mismo modo que las catalanas ${ }^{53}$. Los grandes concejos de la comarca - Graus, Benabarre, Capella y Roda - protestaron conjuntamente ante el rey alegando que nunca habían entregado esta carga, pero el juez averiguó que esta afirmación era falsa - y ciertamente lo era - por lo que sentenció desfavorablemente para los demandantes; además, en la resolución se denuncia la actitud de los ribagorzanos ante los colectores:

«inteliximus vos, simul cum quibusdam hominibus aliorum locorum quibus ipsum bovaticum exigi facimus, comprehendistis inter vos quod ipsum nobis tradere contradiceretis omnino, et quod fuistis cominati collectoribus ipsius eisdem inferre malum si ad dictum locum accederent pro ipso bovatico colligendo» ${ }^{54}$.

A pesar de las quejas, la colecta del bovaje se completó. Sin embargo, menos de tres años después se reprodujo el problema: ante las dificultades financieras de Jaime II, las Cortes catalanas de 1299-1300 acordaron comprar este impuesto a la monarquía, es decir, se decidió su amortización definitiva a cambio de una elevada suma de dinero que se reuniría mediante una carga extraordinaria, en la que también debían colaborar todas las localidades de Ribagorza y La Litera ${ }^{55}$. Los motivos de la oposición que se volvió a suscitar en ambas comarcas se explicitan en una misiva del rey a los recaudadores, en marzo de 1300 , en la que se indicaba que:

«homines de Tamarito et de Sancto Stephano de Littera et quorumdam aliorum locorum Rippacurcie contradicunt imponi et levari in locis ipsis collectam empcionis bovatici nunc ordenatam in celebri Curie Barchinone, asserentes se non debere dare dictam collectam cum sint ad Forum Aragonum populati»s6.

La petición de los representantes de la zona hubo de ser nuevamente rechazada, puesto que en los siguientes meses la colecta continuó, a veces con órdenes específicas para forzar el pago del impuesto en algunas localidades ${ }^{57}$.

La ausencia de un relato mínimamente detallado de las Cortes aragonesas que se reunieron en septiembre de 1300 dificulta la comprensión de las decisiones que allí se tomaron. En un contexto marcado por la amenaza de guerra con Castilla y la persistencia del desencuentro con algunos aristócratas unionis-

53 Sobre el bovaje en el valle de Chistau: ACA, reg. 264, f. 92r. Respecto a Bielsa, en 1279 Alfonso III ordenó una investigación para averiguar si la localidad debía pagar bovaje por ser catalana, o el quinto del ganado aragonés; poco después escribió otra misiva para anular el encargo, puesto que decía tener constancia de que debía pagar la segunda carga (42, ff. 186r y 190r).

54 Ibidem, reg. 254, ff. 4r-5v.

55 SÁNCHEZ, El naixemet, pág. 58.

56 ACA, reg. 115, f. 301r.

57 Ibidem, reg. 257, f. 32v. 
tas, Jaime II planteó unas peticiones económicas similares a las que había formulado en Cataluña para la defensa fronteriza y el pago de sus deudas; la asamblea resolvió esta solicitud consensuando un subsidio que se reuniría mediante una gabela sobre la sal. Al igual que los catalanes, los brazos aragoneses consideraban que Ribagorza y La Litera estaban dentro de sus competencias; de hecho, a la reunión de 1300 acudieron varios notables ribagorzanos y los dos grandes concejos literanos, a pesar de que, como se ha visto, en ambas comarcas se estaba recaudando en aquellos momentos el rescate del bovaje ${ }^{58}$. Durante las negociaciones del auxilio aragonés, hubo de salir a relucir la confusa situación de la zona; la aludida insistencia de los procuradores ribagorzanos y literanos en su oposición a las cargas fiscales catalanas invita a creer que ellos impulsaron que se tratase esta cuestión. En cualquier caso, poco antes de que se cerrase el acuerdo sobre la gabela, se aprobó el fuero Quod Ripacurcia, que situaba la frontera de Aragón en la Clamor de Almacellas, puesto que su primer efecto fue que Ribagorza y La Litera, con sus numerosas explotaciones de sal, quedaron dentro del área de recaudación de la ayuda aragonesa ${ }^{59}$. Resulta obvio que ambos actos de Cortes estaban estrechamente ligados.

La aplicación de esa disposición no fue sencilla en los primeros momentos. Pedro de San Vicente, responsable del subsidio de la sal en Ribagorza, mandó pregonar que, tras la decisión de las Cortes de Zaragoza, quedaba automáticamente suspendido el cobro del rescate del bovaje, lo que incitó a numerosas localidades a negarse a seguir abonándolo. Ante esto, los receptores del auxilio catalán en la comarca, Arnau d'Alòs y Guillem de Fraga, se quejaron ante Jaime II, tal vez porque habían adelantado parte del dinero que se esperaba obtener, lo que forzó una solución de compromiso: se exigió a los concejos que completasen el pago de la compra del bovaje, pero ese importe fue descontado de lo que se pretendía obtener mediante la gabela en la comarca ${ }^{60}$. En todo caso, nunca más se exigió a los ribagorzanos su colaboración en los subsidios catalanes: se había fijado una frontera fiscal.

Frente a la vaguedad e improvisación de las decisiones previas, el fuero Quod Ripacurcia de septiembre de 1300 incluía tres puntos que suponían el definitivo encaje administrativo del territorio en disputa dentro de Aragón. Primero, se estableció un sobrejuntero aragonés para «Rippacurcia, Suprarbium et Valles, et Littera usque ad Clamorem de Almacellis», eligiéndose para el cargo a Jimeno Pérez de Lográn el 12 de octubre de 1300; esto implicó la

58 GONZÁLEZ, Las Uniones, vol. 2, pág. 503.

59 Savall y Dronda, Pascual y PEnÉn y Debesa, Santiago, Fueros, observancias y actos de corte del Reino de Aragón, t. I, Zaragoza, Ibercaja, 1991 [1866], p. 23, fuero Quod Ripacurcia. ACA, reg. 325, f. 8r (29 de septiembre de 1300): en este segundo texto aparecen los primeros mandatos sobre la gabela de la sal y allí se indica que se cobraría «usque ad clamorem Almacellarum; puesto que la Clamor de Almacellas« es una insignificante rambla, su sola alusión significa que ya se había aprobado el fuero Quod Ripacurcia.

60 Ibidem, reg. 257, ff. 32v-33r y 49r. 
exclusión de esta circunscripción del Pallars, que en adelante compartió veguería con Lérida ${ }^{61}$. Segundo, se mandó a todos los oficiales reales que interviniesen en la zona de acuerdo con los Fueros. Y tercero, se ordenó el cumplimiento de todas las ordenanzas aprobadas en las Cortes de Aragón, sin duda, el punto de más amplia repercusión, ya que fijó el marco político y legislativo en que se mantuvo Ribagorza hasta la Nueva Planta borbónica.

Como es sabido, en 1305 las Cortes catalanas acordaron un capítulo que revocaba el fuero Quod Ripacurcia, pero Jaime II lo denegó con los mismos argumentos que los aragoneses le habían expuesto cinco años antes. No obstante, el monarca remitió las posiciones de ambas partes al Justicia de Aragón, Jimeno Pérez de Salanova, para que dictaminase al respecto ${ }^{62}$. La sentencia de este magistrado dio por buenas las razones esgrimidas a favor del aragonesismo de la comarca, y las reforzó con varios datos de índole histórica. Aunque no sepamos si esto pudo influir en la decisión, cabe apuntar que el propio Jimeno tenía el solar de su linaje y principal bien patrimonial en la aldea ribagorzana de Salanova, entre Capella y Fantova.

La argumentación aportada por las Cortes y el Justicia para defender esta decisión se fundamentaba en hechos históricos que, a veces, se remontaban a varios siglos atrás: por ejemplo, se afirmaba que Ribagorza había pertenecido a los reyes del Sobrarbe, que los monarcas aragoneses anteriores a la unión con Barcelona también lo eran de Ribagorza, que Ramiro I había perecido en Graus o, referido a época más reciente, que en el Privilegio General se indicaba expresamente que hubiese sobrejunteros en lugar de vegueres, y que no procediesen de Cataluña. La orden de Jaime II recurría, por el contrario, a un aspecto más práctico: el desconocimiento que los oficiales catalanes tenían de los Fueros aragoneses les impedía aplicarlos adecuadamente ${ }^{63}$.

El principal criterio usado para determinar el trazado de la frontera fue la legislación vigente en cada pueblo: aquellos que se regían por los Fueros se consideraron ribagorzanos y, por ello, se integraron en Aragón; por ejemplo, una orden relacionada con la gabela de 1300 indicaba que esta debía exigirse a todos aquellos «qui sunt ad Forum Aragonum populati in Rippacurcia» ${ }^{64}$. Como consecuencia de este razonamiento, las villas de Arén y Montañana, que usaban las Costumbres de Barcelona, se desvincularon del ámbito ribagorzano para integrarse en la veguería de Pallars hasta que, en 1322, la frontera se ajustó al cauce del río Noguera; también en Entenza se mantuvo este código legal

61 Ibidem, reg. 198, ff. 207r y 337v-338v. La familia Lográn poseyó el feudo de Graus desde comienzos del XIII hasta 1322, lo que hizo de ellos un linaje aristocrático relevante en la comarca, a pesar de que el centro de sus dominios estaba en las altas Cinco Villas.

62 Los documentos están publicados en: MireT, «Documentos inéditos», págs. 51-52; MASIÁ, «La cuestión».

63 ACA, reg. 198, ff. 207r-207v.

64 Ibidem, reg. 325, f. 50r. También se perdonó la gabela a las localidades pobladas a costumbre catalana: f. 38 r. 
gracias a un privilegio de 1312, aunque en este caso siguió dentro de Ribagor$\mathrm{za}$; las tres localidades seguían utilizando la legislación catalana en el siglo $\mathrm{XVI}^{65}$. Por otra parte, también el señor de Calasanz, Guiralt de Cabrera, solicitó la vigencia de la ley catalana en esta villa con un objetivo bien concreto, relacionado con un pleito que sostenía con el vecino lugar de Alins: la «alera foral» aragonesa autorizaba el pasturaje de los ganados en los concejos contiguos al del pastor, lo que sin duda perjudicaba al vecindario y al señor de Calasanz, al abrir las puertas del extenso término a las cabañas de otros pueblos ${ }^{66}$.

Puesto que el poder y rentas de buena parte de la aristocracia ribagorzana derivaba de la posesión de feudos, que se organizaban y justificaban en los Usatges, cabe preguntarse qué supuso para aquella su integración en Aragón. El servicio armado que prestaban al monarca siguió realizándose junto a los catalanes, aunque los ribagorzanos eran anotados separadamente, como muestra el texto algunas convocatorias posteriores a 1300 (por ejemplo: «invocacio ad illos de Cathalonie, Rippacurcie et Pallarensi qui tenentur servire pro feudis»); frente a ellos, los concejos debían servir junto a los aragoneses ${ }^{67}$. Por lo que respecta a la legislación, se mantuvo la dualidad, aunque en cierto modo invertida: si anteriormente existía un Justicia específico en Graus para tratar las causas de acuerdo con los Fueros, en adelante serían los feudos los que figurarían como una excepción legal:

«in Rippacurcia Forum Aragonum, exceptis rebus feudalibus, consueverunt antiquitus et debent nunc etiam observari» 68 .

Indicaciones como esta de 1312 se repiten en bastantes textos, como el mandato del 12 de octubre de 1300 o la donación del condado de Ribagorza al infante Pedro, en $1322^{69}$. Sin embargo, estas garantías no impidieron que se produjesen algunos conflictos entre los oficiales reales y los señores de las castellanías por ese motivo; por ejemplo, uno de ellos, Ramón de Arén, se quejó al rey porque, según afirmó el monarca en una carta al sobrejuntero Guillem de Castellnou:

65 Ibidem, reg. 351, f. 109v (1310); 151, ff. 13v-14r (1312); 366, f. 128v (1321). MASIÁ, «La cuestión», págs. 18-19. BNE, ms. 2070, f. 47r: «la villa y aldeas de Aren y la de Montañana y la Puente de aquella y el lugar y castillo de Entença constitucion y ley de Cathaluña, de manera que la universidad se ha de tratar a Fuero y los particulares a Constitucion» (ca. 1550).

66 ACA, reg. 141, ff. 62r-62v (1307); 142, f. 269v-270r (1308); 143, f. 41v (1309). Tanto en BOIX, «La Ribagorça», como en MONCLÚs, «La Franja de Ponent», se alude a un texto de 1300 en que los vecinos de esta localidad dicen estar poblados «ad Consuetudinem Cataloniae, non ad Forum Aragoniae»; aunque no me ha sido posible localizarlo, deduzco que ha de estar vinculado al mismo pleito.

67 Ibidem, reg. 308, ff. 12r-12v (1309) y 118r (1314).

68 Ibidem, reg. 151, f. 13v.

69 Ibidem, reg. 222, ff. $11 \mathrm{v}-13 \mathrm{v}$. 
«licet antecessores sui et ipse semper usi fuissent jurisdiccione in locis suis de Castanesa, de Valseniu et de Les Pahuls secundum Usum et Consuetudines Cathalonie, vos, aserendo dictum Raimundo uti debere jurisdiccione predicta in locis supradictis secundum Forum Aragonum, ipsum super possesione predictorum indebite perturbatis seu etiam molestatis» ${ }^{70}$.

A pesar de que se mantuviese la legislación catalana en los asuntos feudales, el hecho de que, en la decantación de Ribagorza hacia Aragón o Cataluña, primase el vínculo que los campesinos tenían con el reino, al de los milites con el principado, es un aparente síntoma de la decadencia del segundo grupo. De hecho, aunque la complejidad del asunto impida desarrollarlo aquí, la documentación indica que durante este periodo los ingresos de las castellanías sufrieron un claro bloqueo y nuevos nobles que basaban su poder en la plena potestad sobre sus señoríos sustituyeron a los linajes de castellanes como grupo hegemónico de la aristocracia ribagorzana, al tiempo que algunos de los feudos más relevantes desaparecieron en las posteriores décadas, al ser compradas por las autoridades eclesiásticas (Graus o Besians) o incluso, significativamente, por las propias comunidades rurales (Benabarre, Benasque, Castanesa o Tolva) ${ }^{71}$.

\section{CONCLUSIÓN}

Hasta aquí se ha visto que las dos últimas décadas de la tricésima centuria fueron el periodo decisivo en la fijación de la divisoria entre Cataluña y Aragón de acuerdo con su trazado actual; ahora bien, este hecho fue una fase más dentro del largo proceso de construcción de una frontera cada vez más precisa y relevante. Obviando los precedentes anteriores al año 1200 (límites diocesanos, dependencia de un soberano, etc.), se puede situar su primera etapa en la aparición de una difusa línea entre las áreas de influencia del derecho escrito aragonés o catalán, colocada más al este o al oeste dependiendo del grupo social que observemos; en cierto modo, los conflictos asociados con la Unión encajan en este tipo de problemáticas. El segundo momento está marcado por el auge de una fiscalidad real que precisaba del consenso con las Cortes de ambos territorios; la concreción de un límite lineal que permitiese encuadrar a todas las comunidades rurales en un lado u otro se produjo, como se ha visto, en conexión con esto. Y en una tercera fase, que hasta ahora no se había aludido, esta divisoria adquirió un nuevo significado en tanto que barrera arancelaria: el

70 Ibidem, reg. 153, ff. 237r-237v. Ramón de Areny, aunque no se indique en este texto, disfrutaba de esta jurisdicción en tanto que feudatario de las mencionadas localidades.

71 CDG, doc. 76; CASTILlón CORTADA, Francisco, «La población altoaragonesa de Besians y su dependencia de la catedral de Roda de Isábena», en Homenaje a don Antonio Durán Gudiol, Huesca, Instituto de Estudios Altoaragoneses, 1995, págs. 195-196; ACL, Arcediano de Ribagorza (cajón 59.2), Libro Archiu de Ribagorça, ff. 70r, 85r, 124r-124v y 128r-128v. 
establecimiento de aduanas entre los tres grandes ámbitos políticos de la Corona para financiar las empresas bélicas de la monarquía acarreó que se fragmentase definitivamente este espacio económico ${ }^{72}$; es inconcebible que esto rompiese los lazos existentes, por ejemplo, entre Ribagorza y Pallars, pero sí que se hubo de convertir en la más perceptible evidencia para sus habitantes de que entre ellos se había construido una frontera.

Todos los elementos que tomaron parte en este proceso estaban relacionados con la progresión del poder central de la Corona, por lo que se puede confirmar que «la frontera no existe en sí, sino en relación con el Estado» ${ }^{73}$. La singularidad del caso estudiado radica en que la monarquía aragonesa, en lugar de conformar un espacio unificado, dio lugar a tres ámbitos políticos diferenciados, de modo que se pueden discriminar unos límites internos y otros externos. Sin embargo, esta distinción se debe relativizar: la principal función de la frontera no era la organización de una línea defensiva —al menos durante el periodo estudiado - sino la definición precisa del territorio dependiente del Estado para sujetarlo mejor a su dominio, un papel que desempeñaban igualmente los dos tipos de divisorias; prueba de ello es la nítida vigencia de un límite desprovisto de cualquier connotación militar, como era el que separaba Aragón y Cataluña.

El hecho de que esta divisoria fuese una imposición estatal implica desmentir que la sociedad de las zonas afectadas presentase alguna peculiaridad previa, derivada de una especie de carácter fronterizo per se; pero esto no es óbice para que el proceso descrito situase a Ribagorza, como a La Litera, Fraga o el Bajo Ebro, ante la anómala disyuntiva de tener que escoger por su integración en Aragón o en Cataluña. Además, todas estas comarcas se situaban en posición periférica frente a los centros sociales, políticos, administrativos y culturales de ambos estados de la Corona, de modo que es previsible que presentasen sensibles diferencias con respecto a ellos y que la tendencia iniciada en el siglo XIII a homogeneizar estos espacios tropezara aquí con mayores dificultades. Como resultado, la integración de Ribagorza en uno de los estados fue un proceso conflictivo, no tanto por el enfrentamiento de la monarquía con las diversas fuerzas sociales del país, sino por los choques entre estas últimas por las diferentes opciones que podían tomar ante esa elección.

En su momento, se describieron los perfiles sociales de los partidarios de las dos alternativas que convivieron en Ribagorza entre 1283 y 1300 . Al respecto, llama la atención la implicación de numerosos concejos, un hecho que recuerda a las decenas de síndicos de reducidas comunidades rurales aragonesas que acudieron a las asambleas unionistas con sus agravios, que pone de manifiesto que la sociedad campesina, a través de sus organismos representativos, estaba

72 SeSma MuÑoz, José Ángel, «La fijación de fronteras económicas entre los estados de la Corona de Aragón», en Aragón en la Edad Media, 5 (1983), págs. 141-166.

73 Tomo la frase de PEYVEL, «Structures féodales», pág. 83. 
asumiendo un rol activo y novedoso en la toma de decisiones que les afectaban $^{74}$. Además, la existencia de un conjunto de reivindicaciones comunes apoyadas en los Fueros frente a las instancias monárquicas o señoriales muestra que, al nivel de las élites rurales, se habían difundido una serie de ideas políticas que les llevaban a asociar la integración en Aragón con una mejoría en su condición social. En este sentido, es interesante la comparación de lo aquí descrito con la paralela evolución que tuvo lugar en Ascó, Horta y Miravet, analizada por Pascual Ortega, ya que también allí los concejos defendieron la opción aragonesa frente a unas fuerzas señoriales que se decantaban por Cataluña ${ }^{75}$. Sin embargo, la solución definitiva en el Bajo Ebro fue diametralmente opuesta: el problema perduró durante la primera mitad del siglo XIV y terminó violentamente con el aplastamiento de la insurrección concejil en apoyo de la Unión aragonesa de 1348. La explicación se puede buscar, entre otros factores, en la distinta correlación de fuerzas entre las partes: el control que ejercían las Órdenes Militares sobre las localidades de la Ribera del Ebro debía de ser bastante más intenso y coordinado que el de los feudatarios sobre Ribagorza. Seguramente, los tiempos tampoco eran los mismos.

La perspectiva identitaria — de raíz esencialmente lingüística- desde la que, aún hoy, algunos influyentes sectores intentan explicar la divisoria entre Aragón y Cataluña, al subordinar a aquella cualquier otro argumento, impide todo acercamiento racional a la cuestión. En este artículo se ha pretendido mostrar que la construcción de la frontera no se puede desligar del proceso de formación del Estado feudal avanzado en la Corona de Aragón de los siglos XIII y XIV, el cual permite ofrecer una interpretación plausible de los conflictos que se produjeron paralelamente en algunas comarcas limítrofes. En definitiva, no era la identidad aragonesa o catalana de Ribagorza lo que se jugaba con el trazado de la frontera, sino los intereses de fuerzas sociales enfrentadas.

Recibido: 15-02- 2010

Aceptado: 18-02-2011

74 Oliva Herrer, Hipólito Rafael y CHALlet, Vincent, «La sociedad política y el mundo rural a fines de la Edad Media», en Edad Media. Revista de Historia, 7 (2005-2006), págs. 75-98.

75 ORTEGA, «Aragonesisme i conflicte». 